Article

\title{
Effect of Cation Influx on the Viability of Freeze-Dried Lactobacillus brevis WiKim0069
}

\author{
In Seong Choi ${ }^{1,+}$, Ho Myeong Kim ${ }^{1,+}$, Seung Gon Wi ${ }^{2}$, Ho Hyun Chun ${ }^{1}$, In Min Hwang ${ }^{1}$ \\ and Hae Woong Park ${ }^{1, *}$ \\ 1 R\&D Division, World Institute of Kimchi, Gwangju 61755, Korea; istory@wikim.re.kr (I.S.C.); \\ hmkim@wikim.re.kr (H.M.K.); hhchun@wikim.re.kr (H.H.C.); imhwang@wikim.re.kr (I.M.H.) \\ 2 Asian Pear Research Institute, Chonnam National University, Gwangju 61186, Korea; \\ sgwi_2000@yahoo.co.kr \\ * Correspondence: haewoong@wikim.re.kr; Tel.: +82-62-610-1728 \\ + These authors contributed equally to this work.
}

Received: 21 October 2018; Accepted: 5 November 2018; Published: 8 November 2018

\begin{abstract}
Extension of the storage stability of freeze-dried lactic acid bacteria is important for industrialization. In this study, the effect of cation influx from soy powder, which contains high amounts of cations, as a cryoprotective agent on the viability of freeze-dried Lactobacillus brevis WiKim0069 was tested. Compared to that in the absence of the soy powder, bacterial viability was significantly higher in the presence of soy powder. Approximately $4.7 \%$ of L. brevis WiKim0069 survived in the absence of the protective agent, whereas $92.8 \%$ viability was observed in the presence of soy powder. However, when cations were removed from the soy powder by using ethylenediaminetetraacetic acid (EDTA) and a cationic resin filter, the viability of L. brevis WiKim0069 decreased to $22.9-24.7 \%$. When the soy powder was treated with ethylene glycol tetraacetic acid, the viability was higher than when it was pretreated with EDTA and a cationic resin filter, suggesting that $\mathrm{Mg}^{2+}$ had a role in enhancing the viability of L. brevis WiKim0069. Cold adaptation at $10^{\circ} \mathrm{C}$ prior to freeze-drying had a positive effect on the storage stability of freeze-dried L. brevis WiKim0069, with $60.6 \%$ viability after 56 days of storage. A decrease in the fluorescence polarization value indicated an increase in membrane fluidity, which regulates the activity of ion channels present in the cell membrane. Cold adaptation caused activation of the cation channels, resulting in increased intracellular influx of cations, i.e., $\mathrm{Ca}^{2+}$ and $\mathrm{Mg}^{2+}$. These results suggest that cold adaptation can be used to improve the storage stability of L. brevis WiKim0069.
\end{abstract}

Keywords: Lactobacillus brevis WiKim0069; viability; storage stability; cation; membrane fluidity

\section{Introduction}

Lactic acid bacteria (LAB) play a major role in various fermented foods and beverages, such as kimchi, cheese, yoghurt, and rice wine [1]. Although the quality characteristics of fermented products mainly depend on the LAB species engaged in the fermentation process [2,3], many fermented products depend on natural fermentation by various LAB present in the raw materials, often leading to inconsistent quality of the end products. The backslopping method, in which small amounts of a previous fermentation culture are inoculated into the new batch, has been used on a small scale to prevent fermentation failure. However, for large-scale production for commercialization, a large amount of LAB starters are required to improve sensory quality and guarantee uniform quality of the final products.

An important consideration in the industrial use of $L A B$ is to maintain their viability during the distribution process. Freeze-drying is widely used for long-term storage of LAB starters [4]. However, 
during the process, $\mathrm{LAB}$ cells are exposed to high levels of stress, such as ice crystallization, extreme $\mathrm{pH}$, and low temperature [5,6]. Moreover, the membrane structure of the LAB is often damaged during the process of freezing and thawing, resulting in reduced viability [7]. Protective agents are often employed to enhance the viability of LAB. Various substances have been used as a protective agent, including sugar, polyols, amino acids, and salts [8-11]. However, the protective effects of the agents during the freeze-drying process and subsequent storage vary with the LAB species [12].

There are many reports on the mechanisms of the protective agents with regard to microorganism viability. Different sugars, e.g., sucrose, trehalose, and lactose, have been reported to maintain the stability of the cell membrane through preferential exclusion and replacement of water during freezing and freeze-drying [13]. When glycerol is used as the agent, excessive formation of ice crystals is reduced. The reaction between the amino acid group of nitrogen sources and the carbonyl group of LAB stabilizes protein structure [14]. Both the content of the agents and their different mechanisms caused a difference in viability of LAB [15]. It is known that the osmotic balance inside and outside the cell, regulated by an influx of cations such as calcium or magnesium during freeze-drying, plays an important role in reducing the damage caused by dehydration [16-21]. However, the underlying mechanisms remain largely unclear, as there are few studies because of the difficulty in measuring cation influx.

In this study, the survival rate of Lactobacillus brevis WiKim0069 in the presence or absence of cations, i.e., calcium and/or magnesium, was examined. In addition, the relationship between cation influx and the viability of L. brevis WiKim0069 after freeze-drying was investigated by promoting cation influx.

\section{Materials and Methods}

\subsection{Bacterial Strains and Culture Condition}

Lactobacillus brevis WiKim0069 (KCCM12134P) was used in this study. L. brevis WiKim0069 was cultured in De Man, Rogosa, and Sharpe (MRS) medium (Difco Laboratories, Sparks, MD, USA) at $30{ }^{\circ} \mathrm{C}$ for $24 \mathrm{~h}$ anaerobically. Bacterial cultures were stored in $1.5-\mathrm{mL}$ cryovial tubes (Simport, Beloein, QC, Canada) at $-80{ }^{\circ} \mathrm{C}$ (MDF4V; Panasonic, Tokyo, Japan) to avoid genetic changes due to successive culturing. When necessary, a bacterial stock was thawed at $25^{\circ} \mathrm{C}$ and transferred to a 500-mL Erlenmeyer flask containing $100 \mathrm{~mL}$ of MRS medium.

\subsection{Cation Analysis}

Cationic species $\left(\mathrm{Mg}^{2+}\right.$ and $\left.\mathrm{Ca}^{2+}\right)$ were analyzed by ion chromatography using a Dionex ICS-5000 instrument (Thermo Scientific, Sunnyvale, CA, USA) equipped with a capillary cation exchange column (Dionex IonPac CS12A, $4 \times 250 \mathrm{~mm}$, Thermo Scientific) and a guard column (Dionex IonPac CG12A, $4 \times 50 \mathrm{~mm}$, Thermo Scientific). Methanesulfonic acid $(20 \mathrm{mM})$ was used as the mobile phase and was produced by an eluent generator (Dionex ICS 5000EG, Thermo Scientific). The flow rate was $1 \mathrm{~mL} / \mathrm{min}$. The column temperature was maintained at $30^{\circ} \mathrm{C}$ before injection. Samples were filtered through a $0.45-\mu \mathrm{m}$ syringe filter, and the injection volume was $25 \mu \mathrm{L}$. All the instrumental control and data processing were conducted using Chromeleon System version 7 software (Thermo Scientific).

\subsection{Cation Removal from the Cryoprotective Agent}

Soy powder (Tatua, Morrinsville, New Zealand) was used as food-grade cryoprotective agent to enhance the viability of L. brevis WiKim0069 during freeze-drying. Calcium and magnesium were removed from the agents according to the method reported by Potter and Gergely [22], with slight modification. Cations in the cryoprotective agents were removed using $0.5 \mathrm{M}$ ethylenediaminetetraacetic acid (EDTA) (Sigma, St. Louis, MO, USA), 0.5 M ethylene glycol tetraacetic acid (EGTA) (Sigma), or a cationic resin filter (ZEBA Spin Desalting Columns, Thermo Scientific). Briefly, soy powder was solubilized at $20 \%(w / v)$ in distilled water. Then, $0.5 \mathrm{~mL}$ of $0.5 \mathrm{M}$ EDTA or 
$0.5 \mathrm{M}$ EGTA was added to $10 \mathrm{~mL}$ of cryoprotective agent, mixed for $10 \mathrm{~min}$, and centrifuged at $8000 \times g$ for $10 \mathrm{~min}$. Following completion of cation removal, cation concentrations were measured by ion chromatography as described above.

\subsection{Treatment of L. brevis WiKim0069 with the Cryoprotective Agent}

L. brevis WiKim0069 was cultured in MRS medium anaerobically at $30{ }^{\circ} \mathrm{C}$ for $24 \mathrm{~h}$. The resulting broth was centrifuged at $8000 \times g$ for $10 \mathrm{~min}$ and rinsed three times with sterile $0.9 \%$ saline solution. The cell suspension at concentration of $2 \times 10^{11}$ cells $/ \mathrm{mL}$ was mixed with an equal amount of sterile $20 \%$ solution of soy powder. The same amount of distilled water was used as a control. After they were placed at $4{ }^{\circ} \mathrm{C}$ for $2 \mathrm{~h}$, the suspensions were transferred at $-20^{\circ} \mathrm{C}$ for $2 \mathrm{~h}$ prior to freeze-drying (Freeze-dryer FDB; Operon, Gimpo, Korea) at $-80^{\circ} \mathrm{C}$ for $24 \mathrm{~h}$ [23].

\subsection{Storage Stability Assay}

The broth of $24 \mathrm{~h}$ cultured L. brevis WiKim0069 was subjected to $2 \mathrm{~h}$ of cold stress at $10{ }^{\circ} \mathrm{C}$. It was centrifuged at $8000 \times g$ for $10 \mathrm{~min}$ and rinsed three times with $0.9 \%$ saline solution. The cells were suspended at $1 \times 10^{11}$ cells $/ \mathrm{mL}$ in sterile soy powder solution and transferred to $-20^{\circ} \mathrm{C}$ for $2 \mathrm{~h}$ prior to freeze-drying (Freeze-dryer FDB) at $-80^{\circ} \mathrm{C}$ for $24 \mathrm{~h}$. The freeze-dried samples were stored at $-18{ }^{\circ} \mathrm{C}$ for 56 days.

\subsection{L. brevis WiKim0069 Viability Assay}

The viability of freeze-dried samples was determined periodically. The randomly selected samples were suspended in sterile $0.9 \%$ saline solution, serially diluted, and poured onto MRS plates. After the plates were kept at $30{ }^{\circ} \mathrm{C}$ for $48 \mathrm{~h}$, the number of resulting colonies was converted into bacterial cell number per $\mathrm{mL}$ of the original sample.

\subsection{Confocal Microscopy}

L. brevis WiKim0069 cells were loaded with $5 \mu$ M Fluo-4 AM (Thermo Fisher Scientific Korea, Seoul, Korea) for the detection of $\mathrm{Ca}^{2+}$ and with Mag-Fluo-4 AM (Thermo Fisher Scientific Korea) for the detection of $\mathrm{Mg}^{2+}$ in staining solution $\left(125 \mathrm{mM} \mathrm{NaCl}, 5 \mathrm{mM} \mathrm{KCl}, 2 \mathrm{mM} \mathrm{KH}_{2} \mathrm{PO}_{4}, 4 \mathrm{mM}\right.$ EDTA, $25 \mathrm{mM}$ HEPES, $6 \mathrm{mM}$ glucose; $\mathrm{pH} 7.4$ ) at $30^{\circ} \mathrm{C}$ for $45 \mathrm{~min}$ [24]. The cells were washed three times with staining solution and visualized under a confocal microscope (Zeiss LSM 710; Carl Zeiss, Oberkochen, Germany). Fluo-4 and Mag-Fluo4 were excited at $488 \mathrm{~nm}$, and fluorescence emission was measured at $520 \mathrm{~nm}$.

\subsection{Fluorescence Polarization Measurements}

L. brevis WiKim0069 cells from a 24-h culture were harvested by centrifugation at $5000 \times g$ for $10 \mathrm{~min}$, washed twice with $50 \mathrm{mM}$ morpholineethanesulfonic acid (MES) at pH 6.2, and resuspended in the same buffer. Then, $5 \mu \mathrm{L}$ of 1,6-diphenyl-1,3,5-hexatriene (DHP) solution (in $6 \mathrm{mM}$ tetrahydrofuran) was added to $2 \mathrm{~mL}$ of the cell suspension to obtain a final DHP concentration of $30 \mu \mathrm{M}$ [25]. The cell suspension was vigorously stirred for $1 \mathrm{~min}$ and centrifuged, and the pellet was resuspended in $2 \mathrm{~mL}$ of MES buffer and used immediately for fluorescence polarization (P) measurements at $30{ }^{\circ} \mathrm{C}$ using a microplate reader (SpectraMax i3X, Molecular Devices, Sunnyvale, CA, USA) with excitation and emission at 360 and $430 \mathrm{~nm}$, respectively. $\mathrm{P}$ (which is unitless) was calculated using the following equation:

$$
\mathrm{P}=I_{\|}-I_{\perp} / I_{\|}+I_{\perp},
$$

where $I_{\|}$and $I_{\perp}$ are the fluorescence intensities of the emitted light with the polarization plane parallel and perpendicular to the excitation beam, respectively $[26,27]$. 


\subsection{Statistical Analysis}

Data are presented as the mean of three independent experiments. Data were analyzed using SPSS (Version 19; IBM, Chicago, IL, USA). ANOVA followed by Tukey's HSD test was used to determine significant differences between treatments at $p<0.05$.

\section{Results}

\subsection{Cation Contents in Protective Agent}

The food-grade cryoprotective agent contained divalent cations, i.e., calcium and magnesium, at concentrations ranging from 138 to $500 \mathrm{ppm}$ (Table 1). Soy powder contained $170 \mathrm{ppm}$ of calcium ions and 500 ppm of magnesium ions, respectively. When EDTA, EGTA, or a cationic resin filter was applied to remove divalent cations from soy powder, the cation contents were dramatically reduced. EDTA and cationic resin filter effectively chelated both the divalent cations in the agent, resulting in a $>40 \%$ reduction in the original amounts of cations. EGTA chelated calcium ions rather than magnesium ions.

Table 1. Contents of $\mathrm{Ca}^{2+}$ and $\mathrm{Mg}^{2+}$ in soy powder used as a cryoprotective agent (ppm).

\begin{tabular}{cccccc}
\hline \multirow{2}{*}{ Cryoprotective Agent } & \multirow{2}{*}{ Cation } & \multicolumn{4}{c}{ Cation Chelator } \\
\cline { 3 - 6 } & & None & EDTA & Cationic Resin Filter & EGTA \\
\hline \multirow{2}{*}{ Soy powder } & $\mathrm{Ca}^{2+}$ & 170 & 80 & 72 & 74 \\
& $\mathrm{Mg}^{2+}$ & 500 & 196 & 140 & 413 \\
\hline
\end{tabular}

\subsection{Protective Agent Enhances the Viability of Freeze-Dried L. brevis WiKim0069}

The viability of L. brevis WiKim0069 after freeze-drying was significantly enhanced in the presence of soy powder as a protective agent $(F=1569 ; d f=4,10 ; p<0.001)$ (Figure 1$)$. Approximately $4.7 \%$ of $L$. brevis WiKim0069 survived freeze-drying in the absence of soy powder, whereas viability was $92.8 \%$ in the presence of the protective agent. However, when the soy powder was pretreated with EDTA or a cationic resin filter, the viability of L. brevis WiKim0069 decreased to 22.9-24.7\%. When the soy powder was pretreated with EGTA, the viability was higher than that of EDTA pretreatment, showing $41.8 \%$.

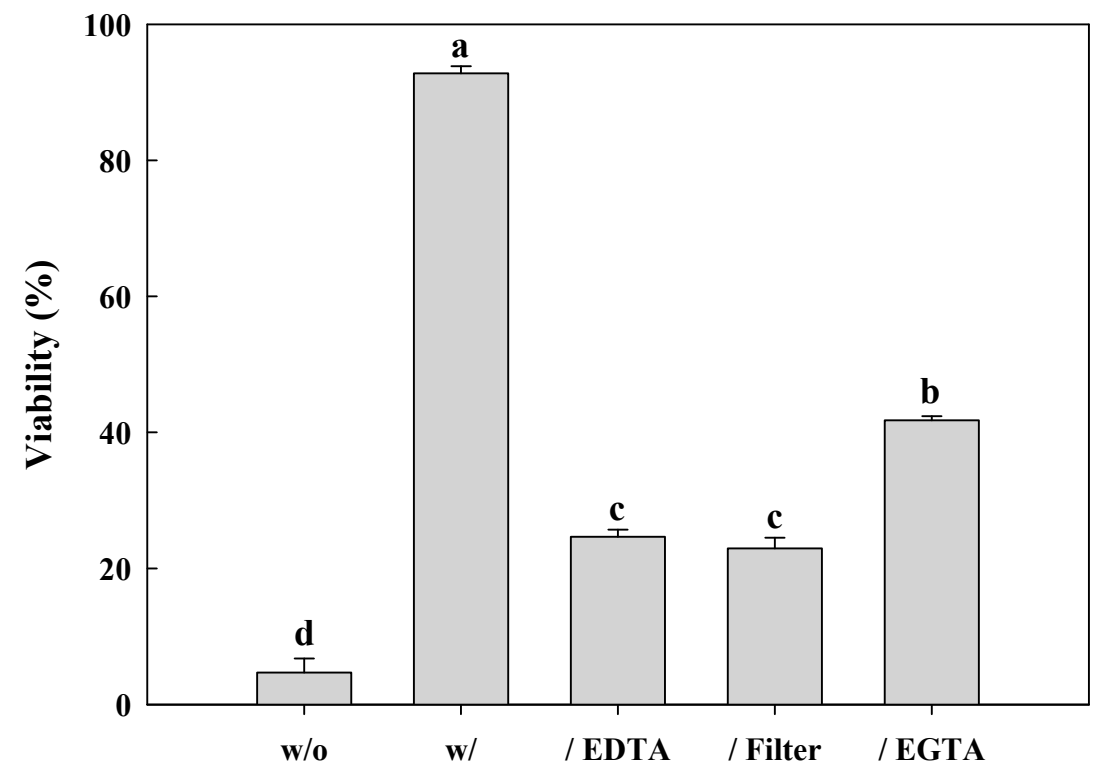

Figure 1. Soy powder improves the viability of freeze-dried Lactobacillus brevis WiKim0069. The graphs show the viability of bacterial cells after freeze drying for $72 \mathrm{~h}$ in the presence or absence of soy powder pretreated or not with ethylenediaminetetraacetic acid (EDTA), a cationic resin filter, or ethylene glycol 
tetraacetic acid (EGTA) to remove cations. w/o: Without soy powder; w/: Soy powder; /EDTA: Soy powder pretreated with EDTA; /Filter: Soy powder pretreated with a cationic filter; /EGTA: Soy powder pretreated with EGTA.

\subsection{Cold Adaption Enhances the Storage Stability of L. brevis WiKim0069 Freeze-Dried in the Presence of Soy Powder}

Cold adaptation at $10^{\circ} \mathrm{C}$ prior to the freeze-drying process had a positive effect on the storage stability of freeze-dried L. brevis WiKim0069 (Figure 2). In the absence of soy powder, no significant effect of cold adaptation at $10{ }^{\circ} \mathrm{C}$ on the viability of L. brevis WiKim0069 was observed. However, in the presence of soy powder, the viability of cold-adapted L. brevis WiKim0069 was increased. Fifty-six days after storage, the viability of cold-adapted L. brevis WiKim0069 was $60.6 \%$, whereas only $37.4 \%$ of cells survived when cold adaptation was not applied, suggesting that cold adaptation enhances the positive effect of soy powder on the storage stability of freeze-dried L. brevis WiKim0069.

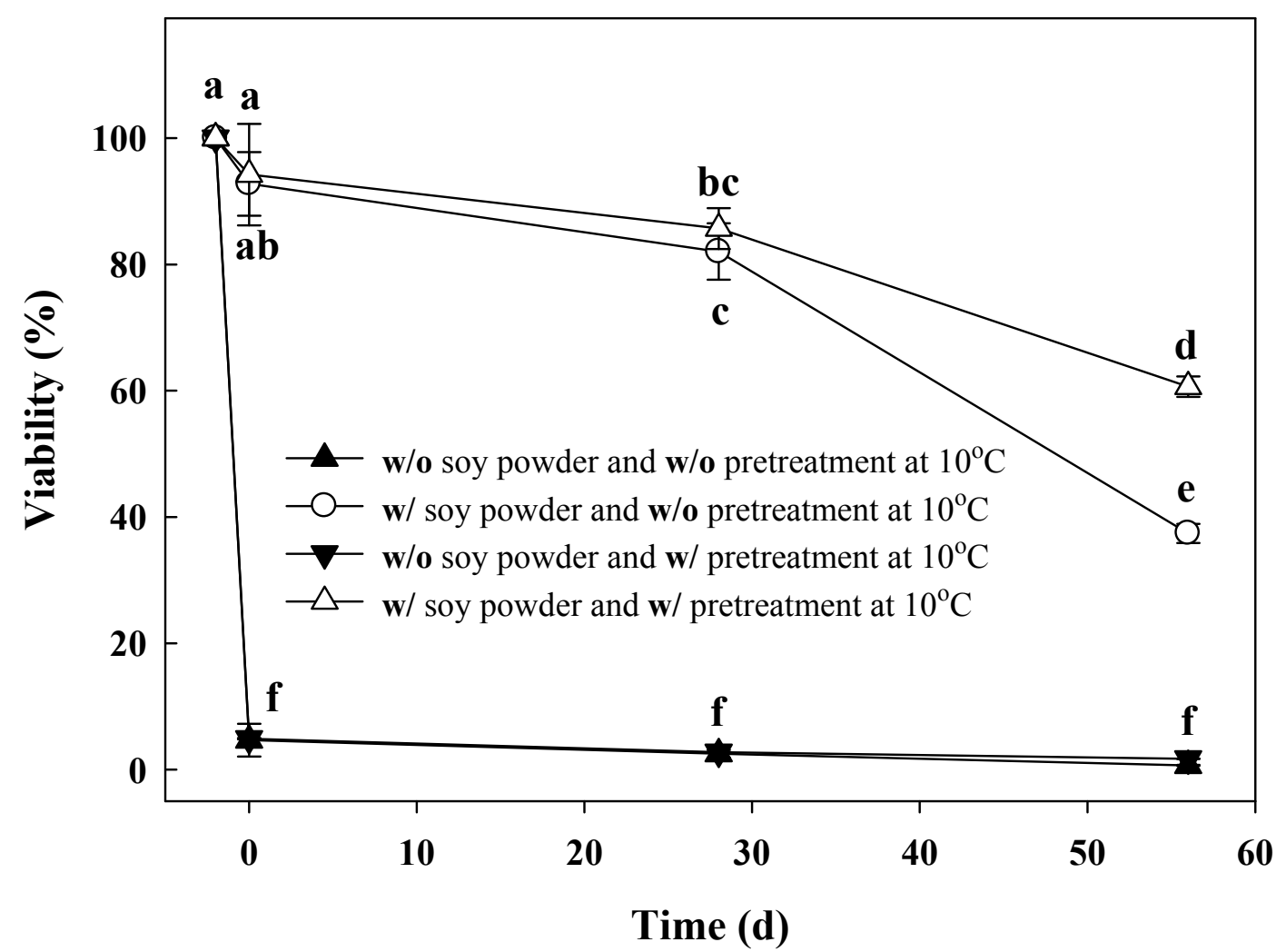

Figure 2. Cold adaption enhances the storage stability of L. brevis WiKim0069 freeze-dried in the presence of soy powder. Storage stability was assessed as the viability of freeze-dried L. brevis WiKim0069 at the indicated time points during storage for 58 days. w/o: Without; w/: With.

\subsection{Cold Adaption Enhances Cation Influx}

To investigate the correlation between viability and cations inside L. brevis WiKim0069 during freeze-drying, the cation influx was measured by confocal microscopy using Fluo-4 AM (to visualize $\mathrm{Ca}^{2+}$ ) and Mag-Fluo-4 AM (to visualize $\mathrm{Mg}^{2+}$ ). Intracellular $\mathrm{Ca}^{2+}$ influx was observed in the presence of soy powder (Figure 3a). $\mathrm{Ca}^{2+}$ influx was further increased when L. brevis WiKim0069 was cold-adapted prior to the freeze-drying process. However, when the soy powder was treated with EDTA, a cationic resin filter, or EGTA, $\mathrm{Ca}^{2+}$ influx was not observed. Similar to $\mathrm{Ca}^{2+}$ influx, $\mathrm{Mg}^{2+}$ influx was observed in the presence of soy powder (Figure 3b). Pretreatment with EDTA or a cationic resin filter caused a reduction in $\mathrm{Mg}^{2+}$ influx, whereas treatment with EGTA had no effect on $\mathrm{Mg}^{2+}$ influx. These results 
indicated that cold adaptation at $10^{\circ} \mathrm{C}$ prior to freeze-drying increases the intracellular cation influx, resulting in enhanced viability of freeze-dried L. brevis WiKim0069.

(a)
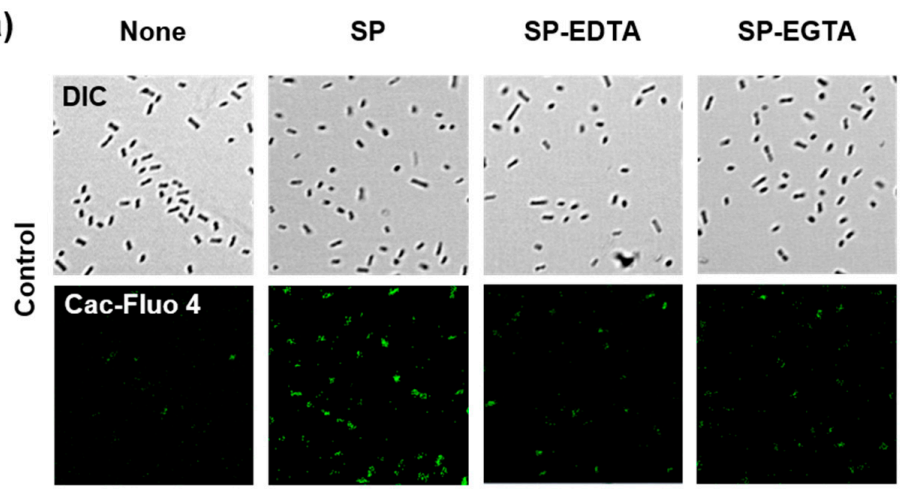

\section{SP-Filter}
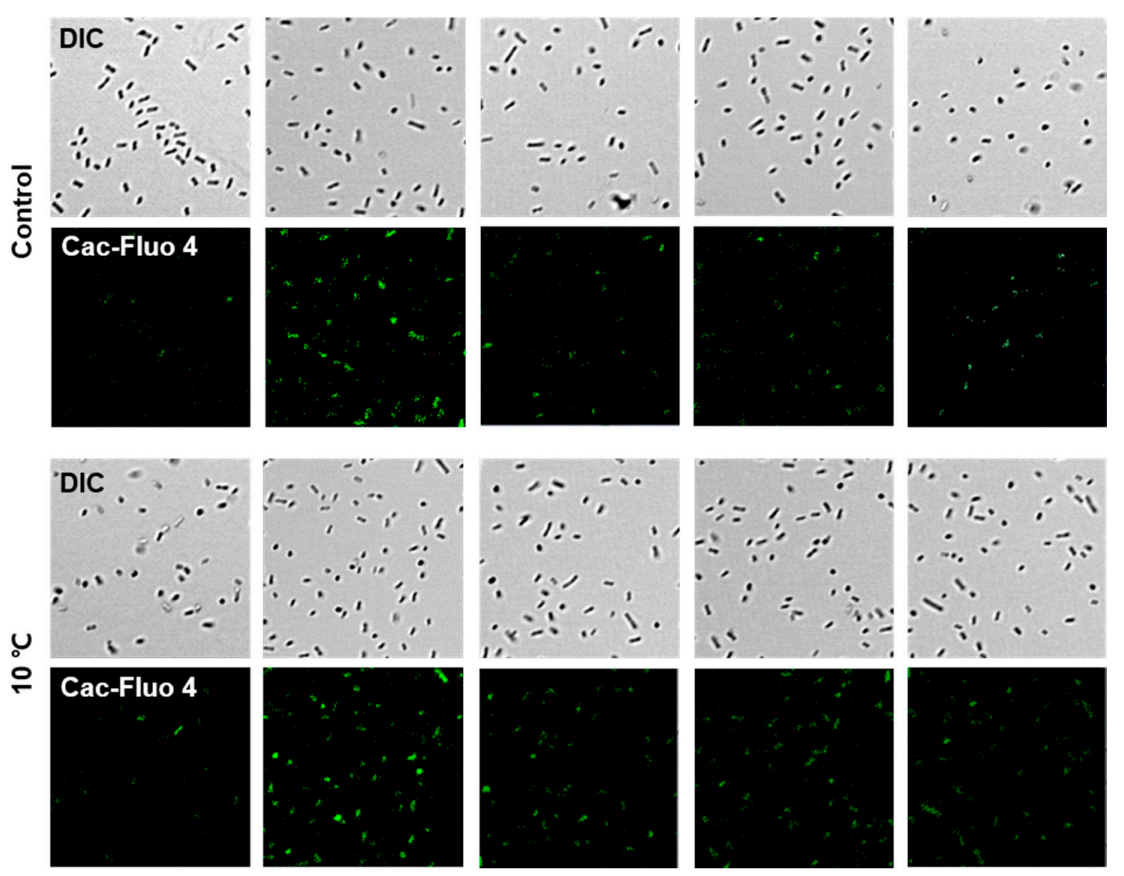

(b)

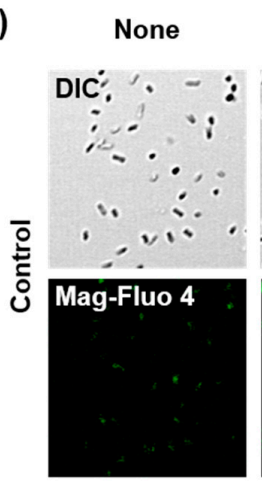

SP
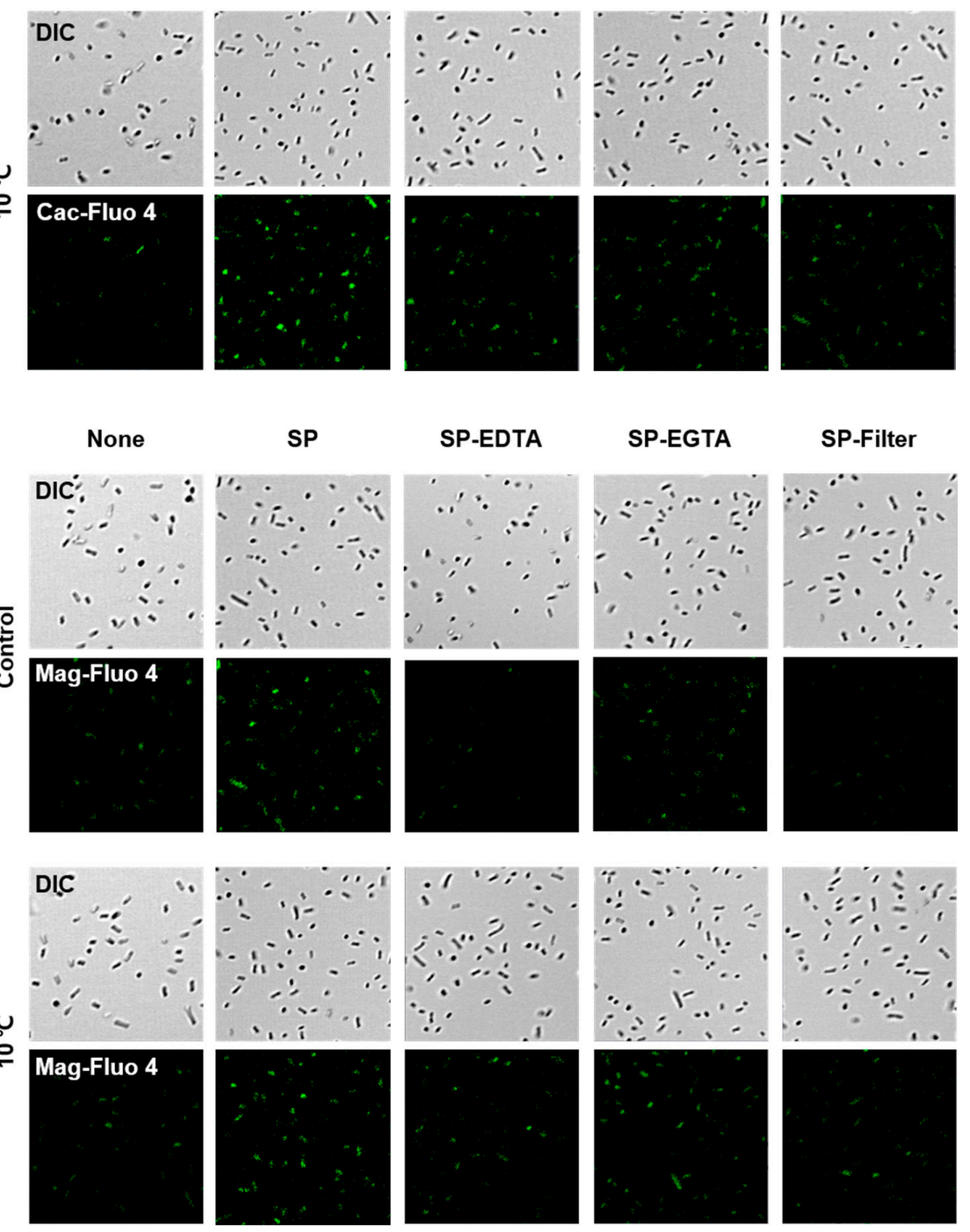

SP-Filter
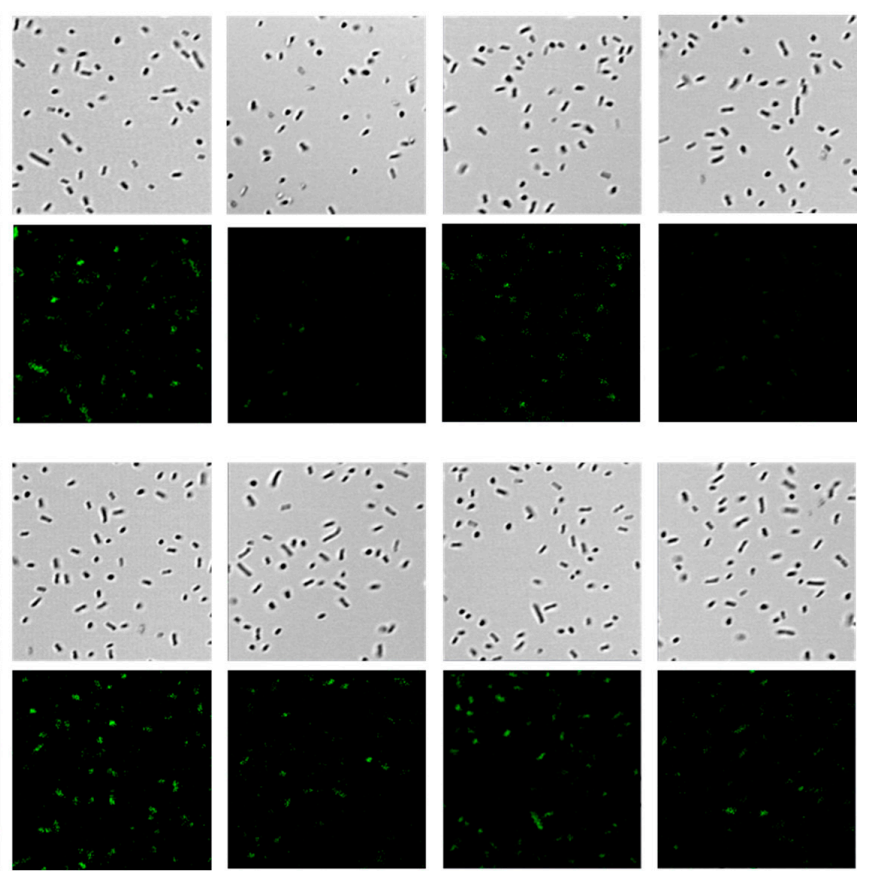

Figure 3. Cold adaption enhances Cation influx into L. brevis WiKim0069 cells in the presence of soy powder. Confocal micrographs revealing $\mathrm{Ca}^{2+}(\mathbf{a})$ and $\mathrm{Mg}^{2+}(\mathbf{b})$ influx into L. brevis WiKim0069 cells under different cryoprotective conditions. SP: Soy powder extract; SP-EDTA: Soy powder pretreated with EDTA; SP-EGTA: Soy powder pretreated with EGTA; SP-Filter: Soy powder pretreated with a cation filter. 


\subsection{Cold Adaption Enhances the Activity of Cation Channels Present in the Bacterial Cell Membrane}

To unravel how intracellular cation influx was induced by cold adaptation, fluorescence polarization was determined as a measure of membrane fluidity, which regulates the activity of ion channels present in the cell membrane (Figure 4). Cold adaptation at $10^{\circ} \mathrm{C}$ prior to freeze-drying resulted in a decrease in the fluorescence polarization value of $0.543 \mathrm{P}$. This result suggested that $\mathrm{Ca}^{2+}$ and $\mathrm{Mg}^{2+}$ influx was increased because of improved cation channel activity caused by increased cell membrane fluidity.

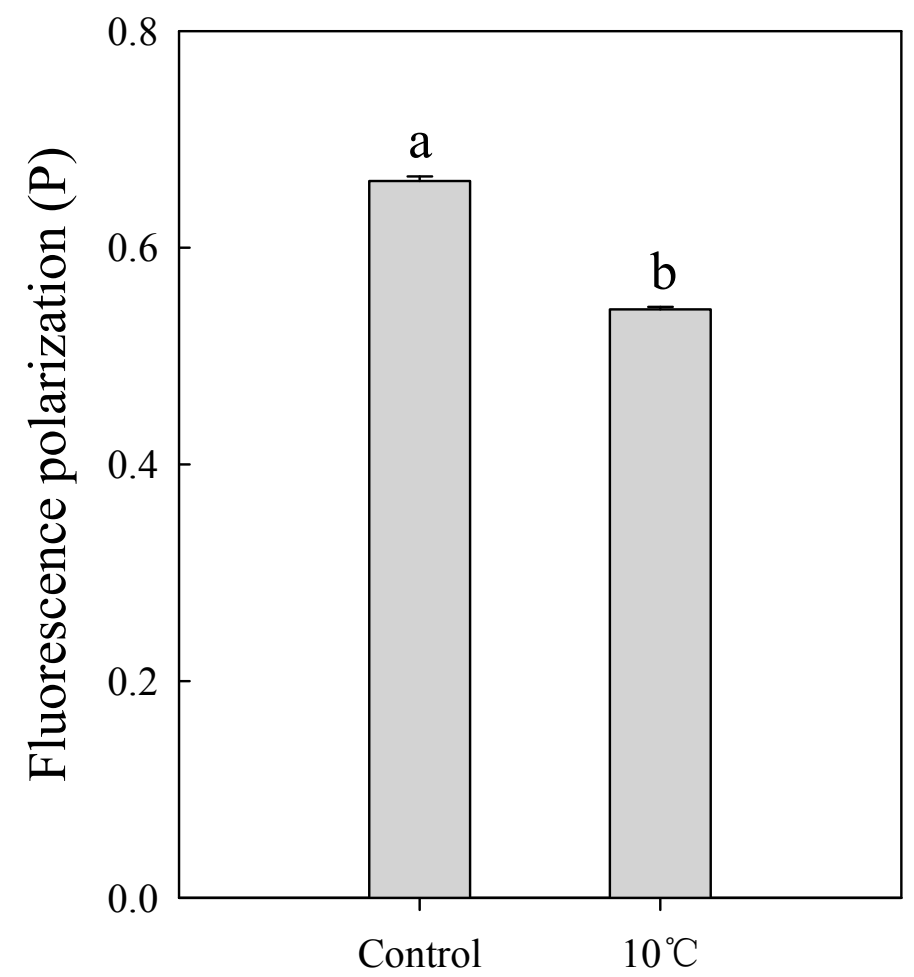

Figure 4. Cold adaption enhances cation influx into the bacterial cells by enhancing cation channel activity in the bacterial cells. Fluorescence polarization of L. brevis WiKim0069 in the presence or absence of cold adaptation.

\section{Discussion}

In our previous study, food-grade soy powder was shown to have a protective effect on LAB cell viability during freeze-drying and subsequent storage [4]. Soy powder contains plenty of amino acids, sugars, and minerals, which could play a role in their cryoprotective effect. However, it remained unclear which component in the protective agent is critical for its effect. In this study, we found that the improved viability of L. brevis WiKim0069 cells freeze-dried in the presence of soy powder could be explained by enhanced cation influx induced by the protective agent. It was clear that increased intracellular $\mathrm{Ca}^{2+}$ and $\mathrm{Mg}^{2+}$ showed a protective effect against detrimental effects of freeze-drying; however, cation influx alone did not explain the difference in viability of L. brevis WiKim0069 when soy powder was used as the protective agent. Further study is required to investigate which soy powder component other than divalent cations plays a crucial role in the protection of L. brevis WiKim0069 during freeze-drying.

Considering the changes observed in the viability of L. brevis WiKim0069 upon pretreatment of the agent with a cation chelator (i.e., EDTA, EGTA, or a resin filter), the amount of cations has a critical impact on cell viability during freeze-drying. Of the two cations tested, calcium ions had a stronger effect than magnesium ions. EDTA has a high affinity for metal ions, and accordingly, the amount of 
cations in soy powder was reduced by half. On the other hand, EGTA is selective for calcium ions and thus, had less effect on the content of magnesium ions. Considering the differential effects of EDTA and EGTA on the amount of cations remaining in the bacterial cells, the viability of L. brevis WiKim0069 was more improved by calcium ions than by magnesium ions.

It is well known that cation influx can enhance the viability of microorganisms through various mechanisms. Increased intracellular calcium ions induce the activation of calcineurin, which is a $\mathrm{Ca}^{2+} /$ calmodulin-dependent serine/threonine protein phosphatase [28,29]. Wang et al. [21] reported that intracellular $\mathrm{Mg}^{2+}$ homeostasis is involved in resistance to external stress. The presence of $\mathrm{Mg}^{2+}$ minimizes the damage caused by osmotic pressure [30,31]. To the best of our knowledge, this study is the first to describe LAB resistance to freeze-drying caused by cation influx, resulting in increased viability of freeze-dried cells. Confocal microscopic observations supported the protective effect of cation influx on freeze-dried LAB. We reason that the accumulation of intracellular cations contributed to the extension of the shelf life of freeze-dried LAB.

Cold adaptation has been extensively studied and found to improve cryotolerance in various bacterial species. Cold stress prior to freezing induces a higher proportion of unsaturated fatty acids in the plasma membrane, which leads to a decrease in the solid-liquid phase transition temperature [32]. Certain fatty acids are closely related to stress responses: C16:0 and C18:2 fatty acids were observed in L. acidophilus grown at low temperature, and C18:1 fatty acids were increased in L. plantarum as a result of low temperature $[33,34]$. In this study, we focused on the effect of cold adaptation on cation influx because intracellular cation concentration was closely related to the viability of L. brevis WiKim0069 cells. Considering the decrease in the fluorescence polarization value after cold adaptation, the membrane fluidity increased with cold stress adaptation, resulting in enhanced cation channel activity. The increased cell viability might thus have resulted from the enhancement of intracellular cation influx.

In conclusion, cation influx enhanced the resistance of L. brevis WiKim0069 to freeze-drying, resulting in increased viability. Intracellular cation accumulation had a positive effect on the shelf life of freeze-dried L. brevis WiKim0069. Considering the differential effects of EDTA and EGTA on the amount of cations remaining in the bacterial cells, the viability of L. brevis WiKim0069 was affected more strongly by calcium than by magnesium ions. Cold adaptation caused activation of the cation channels, increased the intracellular influx of cations, i.e., $\mathrm{Ca}^{2+}$ and $\mathrm{Mg}^{2+}$, and resulted in extension of the storage stability of L. brevis WiKim0069. Thus, our findings emphasize the importance of cation influx on the viability of L. brevis WiKim0069 during freeze-drying and subsequent storage, and support the use of cold adaptation as a means for improving storage stability.

Author Contributions: Conceptualization, H.W.P.; Methodology, I.S.C., H.M.K. and H.H.C.; Formal Analysis, I.M.H.; Investigation, I.S.C., H.M.K. and S.G.W.; Funding acquisition, H.W.P.; Writing-original draft, I.S.C., H.M.K. and H.W.P.

Funding: This research was supported by grants from the Korea Institute of Planning and Evaluation for Technology in Food, Agriculture, Forestry and Fisheries (IPET; 315007-07) and the World Institute of Kimchi (KE1801-1), funded by the Ministry of Science and ICT, Republic of Korea.

Conflicts of Interest: The authors declare no conflict of interest.

\section{References}

1. Leroy, F.; Vuyst, L. Lactic acid bacteria as functional starter cultures for the food fermentation industry. Trends Food Sci. Technol. 2004, 15, 67-78. [CrossRef]

2. Chang, J.Y.; Chang, H.C. Improvements in the quality and shelf life of Kimchi by fermentation with the induced bacteriocin-producing strain, Leuconostoc citreum GJ7 as a starter. J. Food Sci. 2010, 75, 103-110. [CrossRef] [PubMed]

3. Jeong, S.H.; Lee, H.J.; Jung, J.Y.; Lee, S.H.; Seo, H.-Y.; Park, W.-S.; Jeon, C.O. Effects of red pepper powder on microbial communities and metabolites during kimchi fermentation. Int. J. Food Microbiol. 2013, 160, $252-259$. [CrossRef] [PubMed] 
4. Gwak, H.J.; Lee, J.-H.; Kim, T.-W.; Choi, H.-J.; Jang, J.-Y.; Lee, S.I.; Park, H.W. Protective effect of soy powder and microencapsulation on freeze-dried Lactobacillus brevis WK12 and Lactococcus lactis WK11 during storage. Food Sci. Biotechnol. 2015, 24, 2155-2160. [CrossRef]

5. Visick, J.E.; Clarke, S. Repair, refold, recycle: How bacteria can deal with spontaneous and environmental damage to proteins. Mol. Microbiol. 1995, 16, 835-845. [CrossRef] [PubMed]

6. Panoff, J.M.; Thammavongs, B.; Gueguen, M.; Boutibonnes, P. Cold stress responses in mesophilic bacteria. Cryobiology 1998, 36, 75-83. [CrossRef] [PubMed]

7. Wolfe, J.; Bryant, G. Freezing, drying, and/or vitrification of membrane- solute-water systems. Cryobiology 1999, 39, 103-129. [CrossRef] [PubMed]

8. Abadias, M.; Benabarre, A.; Teixido, N.; Usall, J.; Vinas, I. Effect of freeze drying and protectants on viability of the biocontrol yeast Candida sake. Int. J. Food. Microbiol. 2001, 65, 173-182. [CrossRef]

9. Wisselink, H.W.; Weusthuis, R.A.; Eggink, G.; Hugenholtz, J.; Grobben, G.J. Mannitol production by lactic acid bacteria: A review. Int. Dairy J. 2002, 12, 151-161. [CrossRef]

10. Hubalek, Z. Protectants used in the cryopreservation of microorganisms. Cryobiology 2003, 46, $205-229$. [CrossRef]

11. Carvalho, A.S.; Silva, J.; Ho, P.; Teixeira, P.; Malcata, F.X.; Gibbs, P. Protective effect of sorbitol and monosodium glutamate during storage of freeze-dried lactic acid bacteria. Dairy Sci. Technol. 2003, 83, 203-210. [CrossRef]

12. Font de Valdez, G.; de Giori, G.S.; de Ruiz Holgado, A.P.; Oliver, G. Comparative study of the efficiency of some additives in protecting lactic acid bacteria against freeze-drying. Cryobiology 1983, 20, 560-566. [CrossRef]

13. Santivarangkna, C.; Higl, B.; Foerst, P. Protection mechanisms of sugars during different stages of preparation process of dried lactic acid starter cultures. Food Microbiol. 2008, 25, 429-441. [CrossRef] [PubMed]

14. Font de Valdez, G.; de Giori, G.; de Ruiz Holgado, A.P.; Oliver, G. Effect of drying medium on residual moisture content and viability of freeze-dried lactic acid bacteria. Appl. Environ. Microbiol. 1985, 49, 413-415.

15. Yang, C.; Zhu, X.; Fan, D.; Mi, Y.; Luo, Y.; Hui, J.; Su, R. Optimizing the chemical compositions of protective agents for freeze-drying Bifidobacterium longum BIOMA 5920. Chin. J. Chem. Eng. 2012, 20, 930-936. [CrossRef]

16. Aramburu, J.; Heitman, J.; Crabtree, G.R. Calcineurin: A central controller of signalling in eukaryotes. EMBO Rep. 2004, 5, 343-348. [CrossRef] [PubMed]

17. De Lucena, R.M.; Elsztein, C.; Simoes, D.A.; de Morais, M.A., Jr. Participation of CWI, HOG and calcineurin pathways in the tolerance of Saccharomyces cerevisiae to low $\mathrm{pH}$ by inorganic acid. J. Appl. Microbiol. 2012, 113, 629-640. [CrossRef] [PubMed]

18. Groisman, E.A.; Hollands, K.; Kriner, M.A.; Lee, E.J.; Park, S.Y.; Pontes, M.H. Bacterial $\mathrm{Mg}^{2+}$ homeostasis, transport, and virulence. Ann. Rev. Genet. 2013, 47, 625-646. [CrossRef] [PubMed]

19. Jung, U.S.; Sobering, A.K.; Romeo, M.J.; Levin, D.E. Regulation of the yeast Rlm1 transcription factor by the Mpk1 cell wall integrity MAP kinase. Mol. Microbiol. 2002, 46, 781-789. [CrossRef] [PubMed]

20. Walker, G.M. The roles of magnesium in biotechnology. Crit. Rev. Biotechnol. 1994, 14, 311-354. [CrossRef] [PubMed]

21. Wang, H.; Yin, X.; Wu Orr, M.; Dambach, M.; Curtis, R.; Storz, G. Increasing intracellular magnesium levels with the 31-amino acid MgtS protein. Proc. Natl. Acad. Sci. USA 2017, 114, 5689-5694. [CrossRef] [PubMed]

22. Potter, J.D.; Gergely, J. The calcium and magnesium binding sites on troponin and their role in the regulation of myofibrillar adenosine triphosphatase. J. Biol. Chem. 1975, 12, 4628-4633.

23. Santagapita, P.R.; Mazzobre, M.F.; Buera, M.D.P. Invertase stability in alginate beads: Effect of trehalose and chitosan inclusion and of drying methods. Food Res. Int. 2012, 47, 321-330. [CrossRef]

24. Lee, K.J.; Woo, J.S.; Hwang, J.H.; Hyun, C.; Cho, C.H.; Kim, D.H.; Lee, E.H. STIM1 negatively regulates Ca ${ }^{2+}$ release from the sarcoplasmic reticulum in skeletal myotubes. Biochem. J. 2013, 453, 187-200. [CrossRef] [PubMed]

25. Trevors, J.T. Fluorescent probes for bacterial cytoplasmic membrane research. J. Biochem. Biophys. Methods 2003, 57, 87-103. [CrossRef]

26. Martos, G.I.; Minahk, C.J.; de Valdez, G.F.; Morero, R. Effects of protective agents on membrane fluidity of freeze-dried Lactobacillus delbrueckii ssp. bulgaricus. Lett. Appl. Microbiol. 2007, 45, 282-288. [CrossRef] [PubMed] 
27. Yang, X.; Hang, X.; Zhang, M.; Liu, X.; Yang, H. Relationship between acid tolerance and cell membrane in Bifidobacterium, revealed by comparative analysis of acid-resistant derivatives and their parental strains grown in medium with and without Tween 80. Appl. Microbiol. Biotechnol. 2015, 99, 5227-5236. [CrossRef] [PubMed]

28. Fuchs, B.B.; Mylonakis, E. Our paths might cross: The role of the fungal cell wall integrity pathway in stress response and cross talk with other stress response pathways. Eukaryot. Cell 2009, 8, 1616-1625. [CrossRef] [PubMed]

29. Claret, S.; Gatti, X.; Doignon, F.; Thoraval, D.; Crouzet, M. The Rgd1p Rho GTPase-activating protein and the Mid2p cell wall sensor are required at low $\mathrm{pH}$ for protein kinase $\mathrm{C}$ pathway activation and cell survival in Saccharomyces cerevisiae. Eukaryot. Cell 2005, 4, 1375-1386. [CrossRef] [PubMed]

30. Prost, L.R.; Miller, S.I. The Salmonellae PhoQ sensor: Mechanisms of detection of phagosome signals. Cell. Microbiol. 2008, 10, 576-582. [CrossRef] [PubMed]

31. Dalebroux, Z.D.; Miller, S.I. Salmonellae PhoPQ regulation of the outer membrane to resist innate immunity. Curr. Opin. Microbiol. 2014, 17, 106-113. [CrossRef] [PubMed]

32. El-Kest, S.E.; Marth, E.H. Freezing of Listeria monocytogenes and other microorganisms: A review. J. Food Protect. 1992, 55, 639-648. [CrossRef]

33. Fernandez Murga, M.L.; Cabrera, G.M.; Font de Valdez, G.; Disalvo, A.; Seldes, A.M. Influence of growth temperature on cryotolerance and lipid composition of Lactobacillus acidophilus. J. Appl. Microbiol. 2000, 88, 342-348. [CrossRef]

34. Russell, N.J.; Evans, R.I.; Ter Steeg, P.F.; Hellemons, J.; Verheul, A.; Abee, T. Membranes as a target for stress adaptation. Int. J. Food Microbiol. 1995, 28, 255-261. [CrossRef]

(C) 2018 by the authors. Licensee MDPI, Basel, Switzerland. This article is an open access article distributed under the terms and conditions of the Creative Commons Attribution (CC BY) license (http:/ / creativecommons.org/licenses/by/4.0/). 